\title{
Novel Respiratory Impedance-Based Phenotypes Reflect Different Pathophysiologies in Chronic Obstructive Pulmonary Disease Patients
}

This article was published in the following Dove Press journal: International Journal of Chronic Obstructive Pulmonary Disease

\author{
Yumiko Matsuo' \\ Emiko Ogawa ${ }^{1,2}$ \\ Ruriko Seto-Yukimura (D) \\ Yasushi Ryujin ${ }^{1,3}$ \\ Daisuke Kinose' \\ Masafumi Yamaguchi ${ }^{1}$ \\ Makoto Osawa ${ }^{1}$ \\ Taishi Nagao' \\ Hajime Kurosawa ${ }^{4}$ \\ Yasutaka Nakano (iD) \\ 'Division of Respiratory Medicine, \\ Department of Internal Medicine, Shiga \\ University of Medical Science, Shiga, \\ Japan; ${ }^{2}$ Health Administration Center, \\ Shiga University of Medical Science, Shiga, \\ Japan; ${ }^{3}$ Ryujin Medical Clinic, Osaka, \\ Japan; ${ }^{4}$ Center for Environmental \\ Conservation and Research Safety, \\ Department of Occupation Health, \\ Tohoku University, Miyagi, Japan
}

Correspondence: Emiko Ogawa Health Administration Center, Shiga University of Medical Science, Seta Tsukinowa-Cho, Otsu, Shiga 520-2192, Japan

Tel/Fax +8I-77-548-22I 2

Email eogawa@belle.shiga-med.ac.jp
Purpose: The forced oscillation technique (FOT) is a non-invasive method to measure respiratory impedance, the respiratory resistance (Rrs) and reactance (Xrs). The disease probability measure (DPM) is a useful computed tomography (CT) imaging variable for the assessment of gas trapping and emphysema in patients with chronic obstructive pulmonary disease (COPD) using pairs of inspiratory and expiratory CT images. We aimed to develop FOT-based phenotypes and determine whether the phenotypes and their imaging characteristics could facilitate the understanding of COPD pathophysiology.

Patients and methods: FOT and spirometry were examined in 164 COPD patients and 22 non-COPD smokers. COPD patients were divided into four FOT-based phenotypes (NL, normal group; RD, resistance-dominant group; $\mathrm{XD}$, reactance-dominant group; and $\mathrm{MIX}$, mixed group) based on the 3rd quartile values of R5 (Rrs at 5Hz) and X5 (Xrs at 5Hz) in the non-COPD group. The emphysematous lesions and the airway lesions were quantitatively assessed in CT images by low attenuation volume and the square root of the wall area of a hypothetical airway with an internal perimeter of $10 \mathrm{~mm}$ ( $\sqrt{\text { Aaw }}$ at Pi10), respectively. DPM imaging analysis was also performed in 131 COPD patients. We investigated the differences in COPD parameters between the FOT-based phenotypes.

Results: $\sqrt{\text { Aaw at }}$ Pi10 were significantly higher in the RD, XD, and MIX groups than in the NL group. The XD group showed lower pulmonary function and higher dyspnea scores than the RD group. No significant changes in DPM values were observed between the RD and the NL groups. The gas-trapping area was significantly higher in the XD group than in the NL group. The MIX group showed the highest dyspnea score, most emphysematous lesions, and the lowest forced expiratory volume in $1 \mathrm{~s} \%$ predicted value.

Conclusion: The FOT-based phenotyping may be useful to assess pathophysiological changes of COPD with CT assessments.

Keywords: oscillometry, emphysema, exhalation, quantitative evaluation, COPD

\section{Introduction}

Chronic obstructive pulmonary disease (COPD) is a chronic progressive disease with heterogeneous pathophysiology including small airways disease and parenchymal destruction. ${ }^{1,2}$ Computed tomography (CT) is useful for assessing structural abnormalities of airways and lung parenchyma depending on COPD severity. ${ }^{1-3}$

Recently, Galbán et $\mathrm{al}^{4}$ established a new voxel-wise image analysis method called parametric response mapping (PRM) to quantitatively distinguish functional small airway disease with air-trapping from emphysema using digitally co-registered 
inspiration and expiration CT scans. PRM is reported as a useful imaging biomarker for monitoring COPD progression and differentiating COPD phenotypes. $^{5-7}$ Additionally, the disease probability measure (DPM) is a registered voxel classification approach using inspiratory and expiratory CT scans to quantify gas trapping in functional small airways disease. ${ }^{8}$ DPM as well as PRM exhibit associations with pulmonary function measurements and scores in a COPD dyspnea scale. ${ }^{8}$ Although imaging assessment is useful, image analysis takes time and effort.

The forced oscillation technique (FOT), which is used in COPD, is a noninvasive and simple functional assessment method of the airways that measures the respiratory system impedance, consisting of the respiratory system resistance $(\mathrm{Rrs})$ and reactance $(\mathrm{Xrs}))^{9,10} \mathrm{Rrs}$ is a measure of the airway caliber, whereas Xrs reflects the abnormality of parenchyma and airways. ${ }^{9}$ Rrs and Xrs have been independently investigated to ascertain their relationship to other parameters of pulmonary function test and CT scans. ${ }^{9,11}$ However, the relationship between FOT indices and CT imaging parameters remains controversial. ${ }^{11,12}$ Clearly, Rrs and Xrs were not just substitutes for existing COPD parameters.

We hypothesized that the combined assessment of Rrs and Xrs may help elucidate COPD pathophysiology from a new viewpoint, different from spirometry. In this study, we aimed to develop FOT phenotyping based on R5 (Rrs at $5 \mathrm{~Hz}$ ) and X5 (Xrs at $5 \mathrm{~Hz}$ ) for COPD patients and determine whether the phenotypes and their imaging characteristics could facilitate the understanding of COPD pathophysiology, as FOT-based phenotyping may emphasize individually different pathophysiological heterogeneity.

\section{Materials and Methods Subjects and Study Design}

A total of 164 COPD patients and 22 non-COPD smokers who visited the respiratory medicine outpatient clinic of the Shiga University of Medical Science (SUMS) Hospital between August 2013 and November 2016 were enrolled in the SUMS COPD cohort. The non-COPD smokers in this study visited our respiratory medicine outpatient clinic with symptoms such as cough or were referred from general practitioners in order to rule out the presence of COPD due to their history of smoking. The specialists diagnosed the non-COPD smokers using a post-bronchodilator ratio of forced expiratory volume in $1 \mathrm{~s}\left(\mathrm{FEV}_{1}\right) /$ forced vital capacity $(\mathrm{FVC}) \geq 0.70$ according to the GOLD recommendations. ${ }^{13} \mathrm{COPD}$ was diagnosed using a postbronchodilator ratio of $\mathrm{FEV}_{1} / \mathrm{FVC}<0.70$ according to the GOLD recommendations. ${ }^{13,14}$ The eligibility criteria were 1) smoking history of more than 10 pack-years or long-term biomass exposure, 2) no COPD exacerbation in the previous 4 weeks, and 3) apart from asthma no uncontrolled comorbidities, such as severe heart failure, malignant diseases, or other chronic lung diseases. Treatment difference among the study population was based on clinical judgment.

The scores in the COPD assessment test (CAT) ${ }^{15}$ and the modified Medical Research Council (mMRC) dyspnea scale $^{16}$ were recorded for all subjects. Pulmonary function tests, FOT, and paired inspiratory and expiratory chest CT scans were performed in each participant on the same day. This study was approved by the Ethics Committee of SUMS (registration number: 27-11) and conformed to the tenets of the Declaration of Helsinki, and all patients provided written informed consent prior to their participation.

\section{Pulmonary Function Tests}

Spirometry was performed after inhalation of $20 \mu \mathrm{g}$ of procaterol using a FUDAC7 ${ }^{\circledR}$ spirometer (Fukuda Denshi, Tokyo, Japan) according to the American Thoracic Society/ European Respiratory Society guidelines. ${ }^{17}$ Carbon monoxide diffusing capacity was measured by the single-breath washout technique. The predicted values for the spirometry were calculated in accordance with the guidelines of the Japanese Respiratory Society. ${ }^{18}$

\section{Forced Oscillation Technique}

FOT indices were measured after inhalation of $20 \mu \mathrm{g}$ of procaterol using a MostGraph-01 ${ }^{\circledR}$ (Chest M.I., Inc., Tokyo, Japan) at baseline and at follow-up after 2 years. ${ }^{19}$ Briefly, impulse wave signals, which contain multifrequency spectra (4 Hz to $36 \mathrm{~Hz}$ ) generated by loudspeakers at intervals of 0.25 seconds, were applied to the subject's respiratory system via a mouthpiece. The mouth pressure and flow signals were recorded during the patient's tidal breathing at rest. Patients' cheeks were supported during measurement of respiratory impedance. The FOT indices at each oscillatory frequency $(4-35 \mathrm{~Hz})$, such as Rrs and Xrs at 5 or $20 \mathrm{~Hz}$ (R5, R20, and X5), the resonant frequency (Fres), and the low-frequency reactance (ALX), were calculated automatically using fast Fourier transformation methods. 
Each oscillatory index was expressed as the mean value of five entire respiratory cycles.

\section{Novel FOT-Based Phenotypes}

The 164 COPD patients were divided into four phenotypes (NL, normal group; RD, resistance-dominant group; XD, reactance-dominant group; and MIX, mixed group) based on the 3rd quartile values of $\mathrm{R} 5$ and $\mathrm{X} 5$ in the non-COPD group. With an R5 and X5 cut-off value of 0.214 and $-0.057 \mathrm{kPa} / \mathrm{L} / \mathrm{s}$, respectively, the numbers of patients in the NL, RD, XD, and MIX groups were 69, 22, 12, and 61, respectively (Figure 1).

\section{Inspiratory and Expiratory Chest CT}

Volumetric non-contrast chest CT was performed in the supine position using a 320-detector row CT scanner, the Aquilion $\mathrm{ONE}^{\circledR}$ (Canon Medical Systems Corporation, Tochigi, Japan), with either full inspiration or full expiration after inhalation of $20 \mu \mathrm{g}$ of procaterol. CT images

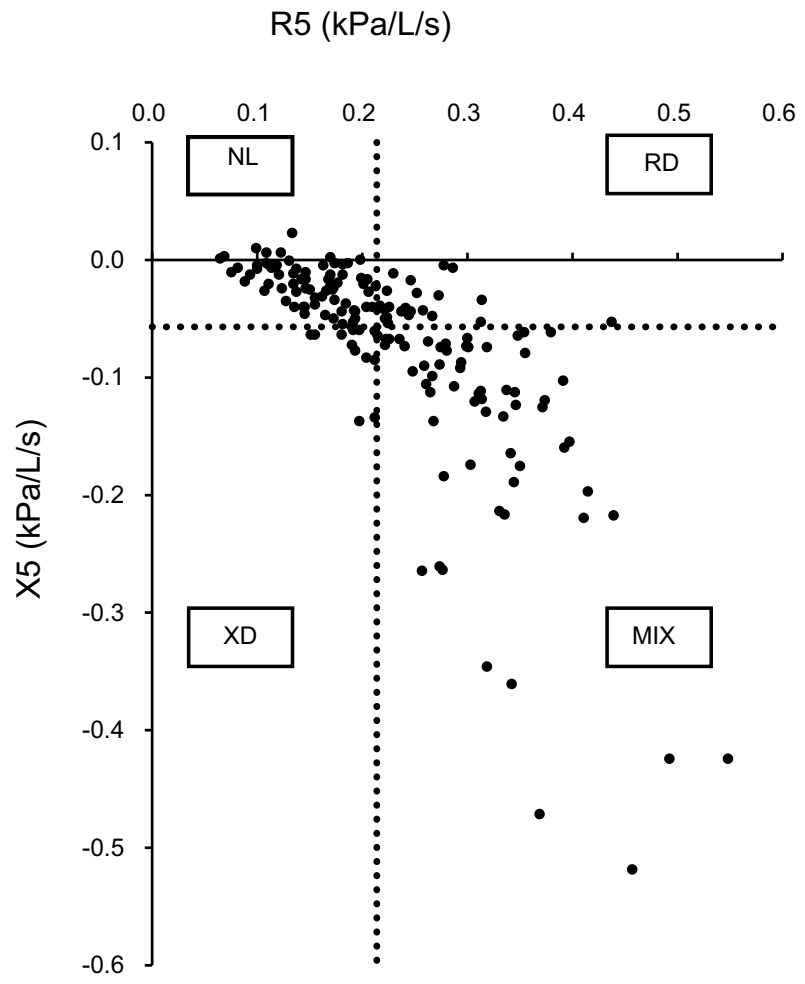

Figure I Definition of the four novel FOT-based phenotypes in COPD patients. The vertical and horizontal dashed lines show the 3 rd quartile value for R5 $=0.214$ and $X 5=-0.057$, respectively, in the non-COPD smokers. Using these cut-off values, 164 COPD patients were divided into four phenotypes.

Abbreviations: NL, normal group; RD, resistance-dominant group; XD, reactancedominant group; MIX, mixed group; FOT, forced oscillation technique; R5, respiratory system resistance at $5 \mathrm{~Hz} ; \mathrm{X} 5$, respiratory system reactance at $5 \mathrm{~Hz}$. were reconstructed with $1.0-\mathrm{mm}$ slice thickness and 0.5 -mm intervals using the FC03 algorithm.

The percentage of low attenuation volume (LAV\%), one of the characteristic parameters of emphysematous lesions, were defined as voxels with $\mathrm{CT}$ attenuation less than -950 Hounsfield units. LAV\% and the square root of the wall area of a hypothetical airway with an internal perimeter of $10 \mathrm{~mm}(\sqrt{ }$ Aaw at $\mathrm{Pi10}),{ }^{3}$ an index reflecting airway lesions, were quantitatively measured using the Apollo ${ }^{\circledR}$ software (VIDA, Coralville, IA, USA) as previously described. ${ }^{2,20}$

\section{DPM}

DPM is a quantitative voxel analysis based on the registration of paired inspiration and expiration CT scans as previously reported by Kirby et al. ${ }^{8}$ Briefly, DPM classifies each voxel as normal $\left(\mathrm{DPM}_{\text {Normal }}\right)$, emphysematous $\left(\mathrm{DPM}_{\mathrm{Emph}}\right)$, or gas trapping, referred to as functional small airways disease $\left(\mathrm{DPM}_{\mathrm{GasTrap}}\right)$ by a combination of the probability of gas trapping and the probability of emphysema calculated by inspiratory-to-expiratory intensity differences. DPM analyses were performed by VIDA as previously described. ${ }^{8}$ Representative colored DPM map images of a nonCOPD smoker and a COPD patient are shown in Supplementary Figure 1.

\section{Statistical Analysis}

Statistical analyses were performed using the JMP software ver.11 (SAS Institute, Cary, NC, USA). The differences between the COPD and non-COPD groups and comparisons between FOT-based phenotypes were evaluated using the Wilcoxon rank-sum test. A value of $p<0.05$ was considered statistically significant.

\section{Results \\ Characteristics of COPD Patients and Non-COPD Smokers}

Table 1 shows the baseline characteristics of the study population. Overall, most participants were men, and most COPD patients had mild or moderate airflow limitation. The FOT indices are presented in Table 2. R5 and R20 were significantly higher in COPD patients than in non-COPD smokers. Although no significant differences in Xrs indices were detected between subjects with and without COPD, X5 tended to be lower while Fres and ALX tended to be higher in COPD patients. 
Table I Characteristics of the Study Subjects

\begin{tabular}{|c|c|c|c|}
\hline & $\begin{array}{l}\text { COPD } \\
(n=164)\end{array}$ & $\begin{array}{l}\text { Non-COPD } \\
(\mathrm{n}=22)\end{array}$ & p-Value \\
\hline $\begin{array}{l}\text { Age (years) } \\
\text { Sex (male/female) } \\
\text { BMI }\left(\mathrm{kg} / \mathrm{m}^{2}\right)\end{array}$ & $\begin{array}{l}72.2 \pm 8.1 \\
152 / 12 \\
23.2 \pm 3.2\end{array}$ & $\begin{array}{l}70.6 \pm 9.3 \\
21 / 1 \\
22.6 \pm 2.3\end{array}$ & $\begin{array}{l}\text { N.S. } \\
\text { N.S. }\end{array}$ \\
\hline $\begin{array}{l}\text { Smoking history } \\
\text { Current/former/never }{ }^{\dagger} \\
\text { Pack-years } \\
\text { mMRC score } \\
\text { Total CAT score }\end{array}$ & $\begin{array}{l}33 / 129 / 2 \\
59.6 \pm 30.1 \\
1.2 \pm 1.1 \\
10.5 \pm 7.3\end{array}$ & $\begin{array}{l}4 / 18 / 0 \\
58.3 \pm 38.6 \\
0.9 \pm 1.0 \\
10.0 \pm 8.0\end{array}$ & $\begin{array}{l}\text { N.S. } \\
\text { N.S. } \\
\text { N.S. }\end{array}$ \\
\hline $\begin{array}{l}\text { Pulmonary function tests } \\
\text { VC (L)" } \\
\text { FEV }_{1}(\mathrm{~L})^{\pi} \\
\text { FEV }_{1} / \mathrm{FVC}(\%)^{\pi} \\
\mathrm{FEV}_{1} \% \text { predicted }(\%)^{\pi} \\
\mathrm{DL}_{\mathrm{co}} / \mathrm{VA}(\mathrm{mmol} / \mathrm{min} / \mathrm{kPa} / \mathrm{L})^{\S}\end{array}$ & $\begin{array}{l}3.5 \pm 0.8 \\
1.9 \pm 0.7 \\
54.2 \pm 12.4 \\
70.5 \pm 21.6 \\
0.9 \pm 0.4\end{array}$ & $\begin{array}{l}3.3 \pm 0.7 \\
2.4 \pm 0.5 \\
74.3 \pm 3.2 \\
88.1 \pm 15.0 \\
1.1 \pm 0.4\end{array}$ & $\begin{array}{l}\text { N.S. } \\
0.0003 \\
<0.0001 \\
0.0002 \\
\text { N.S. }\end{array}$ \\
\hline $\begin{array}{l}\text { GOLD airflow limitation } \\
\text { severity } \\
\text { I/2/3/4 }\end{array}$ & $56 / 80 / 21 / 7$ & - & \\
\hline
\end{tabular}

Notes: Data are presented as the mean \pm standard deviation unless otherwise stated and were analyzed by Wilcoxon's rank-sum test. 'inhalation biomass; ${ }^{\top} n=163{ }^{\S} n=158$. Abbreviations: BMI, body mass index; CAT, COPD assessment test; COPD, chronic obstructive lung disease; $\mathrm{DL}_{\mathrm{co}} / \mathrm{VA}$, carbon monoxide diffusing capacity of the lung for carbon monoxide and alveolar volume ratio; $\mathrm{FEV}_{1}$, forced expiratory volume in I s; FVC, forced vital capacity; GOLD, Global Initiative for Chronic Obstructive Lung Disease; mMRC, modified Medical Research Council dyspnea scale; N.S., not significant ( $P>0.05)$; VC, vital capacity.

Table 2 Comparison of FOT Indices Between COPD Patients and Non-COPD Smokers

\begin{tabular}{|l|l|l|l|}
\hline & $\begin{array}{l}\text { COPD } \\
(\mathbf{n}=\mathbf{~ 1 6 4})\end{array}$ & $\begin{array}{l}\text { Non-COPD } \\
(\mathbf{n}=\mathbf{2 2})\end{array}$ & p-Value \\
\hline $\mathrm{R} 5(\mathrm{kPa} / \mathrm{L} / \mathrm{s})$ & $0.23 \pm 0.09$ & $0.18 \pm 0.05$ & $<0.05$ \\
$\mathrm{R} 20(\mathrm{kPa} / \mathrm{L} / \mathrm{s})$ & $0.18 \pm 0.06$ & $0.15 \pm 0.04$ & $<0.01$ \\
$\mathrm{R} 5-\mathrm{R} 20(\mathrm{kPa} / \mathrm{L} / \mathrm{s})$ & $0.05 \pm 0.04$ & $0.03 \pm 0.02$ & N.S. \\
X5 $(\mathrm{kPa} / \mathrm{L} / \mathrm{s})$ & $-0.08 \pm 0.09$ & $-0.05 \pm 0.05$ & N.S. \\
Fres $(\mathrm{Hz})$ & $11.37 \pm 5.57$ & $9.01 \pm 3.32$ & N.S. \\
ALX $(\mathrm{kPa} / \mathrm{L}$ & $0.54 \pm 0.90$ & $0.23 \pm 0.41$ & N.S. \\
s Hz) & & & \\
\hline
\end{tabular}

Notes: Data are presented as the mean \pm standard deviation and were analyzed by Wilcoxon's rank-sum test. Each oscillatory index was expressed as the mean value of five entire respiratory cycles.

Abbreviations: $A L X$, low-frequency reactance area; Fres, resonant frequency; $N$. S., not significant ( $>$ > 0.05); R5, Rrs at $5 \mathrm{~Hz}$; R20, Rrs at $20 \mathrm{~Hz}$; R5-R20, difference from R5 to R20; X5, Xrs at $5 \mathrm{~Hz}$.

\section{Differences Among FOT-Based Phenotypes}

Table 3 shows the comparisons among these FOT-based phenotypes. The XD and MIX groups were older and showed significantly higher scores in the mMRC dyspnea scale than the NL and RD groups. The $\mathrm{FEV}_{1} \%$ predicted values were significantly lower in the XD and MIX than in the NL and RD groups. The minimum of the LAV\% values was determined in the $\mathrm{RD}$ group and was significantly different from that in the MIX group, which presented the highest value of all groups ( $p<0.05$; Table 3 ). Furthermore, $\sqrt{\text { Aaw }}$ at Pi10 was significantly higher in the RD, XD, and MIX groups than in the NL group.

\section{DPM}

The distribution of DPM parameters in the categories based on the defined FOT phenotypes is presented in Figure 2. No significant differences in DPM parameters were noted between the RD and NL groups. In the XD group, the percentage of $\mathrm{DPM}_{\mathrm{Emph}}$ did not significantly differ from that in the NL group, but the $\mathrm{DPM}_{\text {GasTrap }}$ value was significantly increased. The values for DPM $\mathrm{Normal}_{\text {and }} \mathrm{DPM}_{\mathrm{GasTrap}}$ differed significantly between the MIX and the NL groups, and DPM $M_{\text {Emph }}$ was significantly higher than that in the RD group.

\section{Comparison of FOT-Based Phenotypes with GOLD-Based Severity of Airflow}

\section{Limitation}

Figure 3 shows the distribution of FOT-based phenotypes in relation to the severity of airflow limitation according to the GOLD classification. Although subjects in the RD, XD, and MIX groups were present in the GOLD 1 category, it was mostly composed of NL subjects. The percentages of study participants from the XD and MIX groups increased with increased severity of airflow limitation, and the GOLD 4 category consisted only of subjects from the MIX group. The RD group was mainly present in categories GOLD 1 and 2.

\section{Discussion}

We proposed a novel FOT-based phenotyping for combined assessment of Rrs and Xrs. The FOT-based phenotyping may emphasize individually on the different pathophysiological backgrounds with the same level of pulmonary function severity. The FOT-based phenotyping may be useful to assess pathophysiological changes of airway lesions and emphysema comprehensively.

In COPD, Rrs tends to increase, while Xrs tends to decrease with an increased degree of airflow obstruction. ${ }^{19}$ Di Mango et al reported that airway obstruction in the initial phase of COPD can be represented mainly by the resistive parameters, while the reactive parameters gain importance in more advanced stages. ${ }^{21}$ However, in this study, we revealed a different phenotype which X5 was predominantly 
Table 3 Characteristics, Pulmonary Functions, and CT Imaging Biomarkers Among FOT-Based Phenotypes

\begin{tabular}{|c|c|c|c|c|}
\hline & NL $(n=69)$ & $\operatorname{RD}(n=22)$ & $X D(n=12)$ & $\operatorname{MIX}(n=6 I)$ \\
\hline Age & $69.8 \pm 8.1$ & $69.7 \pm 8.8$ & $78.3 \pm 5.4 * * * *$ & $74.7 \pm 6.8^{*} * * *$ \\
\hline Sex (male/female) & $67 / 2$ & $20 / 2$ & $10 / 2$ & $55 / 6$ \\
\hline BMI $\left(\mathrm{kg} / \mathrm{m}^{2}\right)$ & $22.5 \pm 2.9$ & $24.0 \pm 3.2$ & $23.8 \pm 3.7$ & $23.6 \pm 3.4^{*}$ \\
\hline pack-years $^{\dagger}$ & $56.7 \pm 26.8$ & $49.3 \pm 23.7$ & $52.6 \pm 29.8$ & $64.9 \pm 37.1$ \\
\hline mMRC score ${ }^{\pi}$ & $0.9 \pm 1.0$ & $0.7 \pm 0.6$ & $1.6 \pm 1.0 * * *$ & $1.6 \pm 1.1 *, * *$ \\
\hline Total CAT score ${ }^{\S}$ & $8.4 \pm 6.5$ & $10.1 \pm 7.4$ & $13.5 \pm 8.6^{*}$ & $12.4 \pm 7.4 *$ \\
\hline Pulmonary function tests & NL $(n=68)$ & $R D(n=22)$ & $X D(n=12)$ & $\operatorname{MIX}(n=6 I)$ \\
\hline $\mathrm{FEV}_{\text {, (L) }}$ & $2.3 \pm 0.5$ & $2.0 \pm 0.6^{*}$ & $1.5 \pm 0.5^{*} * *$ & $1.4 \pm 0.5^{*}, * *$ \\
\hline $\mathrm{FEV}_{\mathrm{l}} / \mathrm{FVC}(\%)$ & $60.3 \pm 8.1$ & $57.5 \pm 9.5$ & $49.8 \pm 13.6^{*}$ & $46.7 \pm 13.2^{* * * *}$ \\
\hline FEV $\%$ \%predicted (\%) & $82.0 \pm 16.6$ & $76.0 \pm 16.1$ & $60.1 \pm 20.3 * * *$ & $57.0 \pm 20.5^{*} * *$ \\
\hline VC (L) & $3.9 \pm 0.7$ & $3.7 \pm 0.7$ & $3.1 \pm 0.7^{*}, * *$ & $3.1 \pm 0.7^{*}, * *$ \\
\hline $\mathrm{DL}_{\mathrm{co}} / \mathrm{VA}(\mathrm{mmol} / \mathrm{min} / \mathrm{kPa} / \mathrm{L})^{\ddagger}$ & $0.9 \pm 0.4$ & $1.0 \pm 0.3$ & $0.9 \pm 0.5$ & $0.8 \pm 0.4^{* *}$ \\
\hline CT imaging biomarkers & NL $(n=55)$ & $\operatorname{RD}(n=19)$ & $X D(n=9)$ & $\operatorname{MIX}(n=49)$ \\
\hline LAV\% (\%) & $11.3 \pm 9.9$ & $7.9 \pm 7.9$ & $14.8 \pm 14.5$ & $15.7 \pm 12.6^{* *}$ \\
\hline$\sqrt{\text { Aaw }}$ at Pil0 $(\mathrm{mm})$ & $3.69 \pm 0.06$ & $3.74 \pm 0.06 *$ & $3.76 \pm 0.08 *$ & $3.77 \pm 0.06 * * *$ \\
\hline
\end{tabular}

Notes: Data are presented as the mean \pm standard deviation and were analyzed by Wilcoxon's rank-sum test. ${ }^{\dagger} n=67(N L), 22(R D), 12(X D)$, and $6 I(M I X) ;{ }^{\pi} n=69(N L)$, 2 I (RD), 12 (XD), and 60 (MIX); ${ }^{\S} n=68$ (NL), 21 (RD), 12 (XD), and 61 (MIX); ${ }^{\ddagger} n=67$ (NL), 22 (RD), 12 (XD), and 57 (MIX). *P < 0.05 vs NL; **P < 0.05 vs RD. Abbreviations: $\sqrt{A a w}$ at Pil0, square root of the wall area of a hypothetical airway with an internal perimeter of $10 \mathrm{~mm}$; $\mathrm{BMI}$, body mass index; CAT, COPD assessment test; $\mathrm{CT}$, computed tomography; $\mathrm{DL}_{\mathrm{CO}} / \mathrm{VA}$, carbon monoxide diffusing capacity of the lung for carbon monoxide and alveolar volume ratio; FEVI, forced expiratory volume in I s; FOT, forced oscillation technique; FVC, forced vital capacity; LAV\%, percentage of low attenuation volume; MIX, mixed group; mMRC, modified Medical Research Council dyspnea scale; NL, normal group; RD, resistance-dominant group; VC, vital capacity; XD, reactance-dominant group.

decreased. The XD group shows lower pulmonary function and higher dyspnea scores than the RD group. In addition, the increase in the gas-trapping area concomitant with the decrease in normal area was observed in the XD group by imaging analysis. The XD group may be the previous stage of CT-based emphysema type. ${ }^{22-24}$ On the contrary, the RD group corresponds to CT-based airway dominant type by considering the values of $\sqrt{\text { Aaw }}$ at $\mathrm{Pi10}$ and $\mathrm{LAV} \%$. The

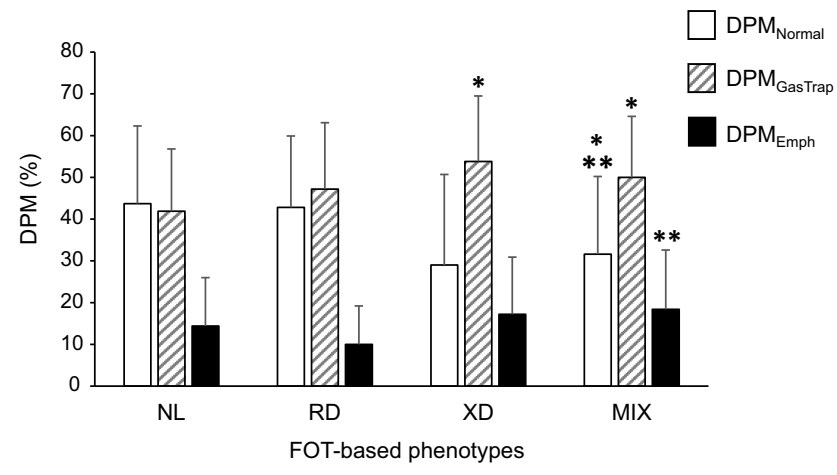

Figure 2 Distribution of the DPM parameters according to the FOT -based phenotypes. Bars show the data presented as the mean \pm standard deviation of DPM $_{\text {Normal }}$ (white), DPM GasTrap (shaded), and DPM Emph (black). The numbers of subjects are in 52, 21,8 , and 46 in the NL, RD, XD, and MIX groups, respectively. The Wilcoxon rank-sum test was used to compare DPM parameters among groups. ${ }^{*} p<0.05$ compared with NL; **p $<0.05$ compared with RD.

Abbreviations: DPM, disease probability measure; DPM ${ }_{\text {GasTrap }}$ gas trapping lesion recognized by DPM; DPM Emph $_{\text {, emphysematous lesion recognized by DPM; DPM }}$ Normal, normal lesion recognized by DPM; FOT, forced oscillation technique; MIX, mixed group; $\mathrm{NL}$, normal group; RD, resistance-dominant group; $X D$, reactance-dominant group. features of the MIX group are in line with our previous observation that a combined airway and parenchymal phenotype in the assessment of CT images is associated with more severe airflow limitation and dyspnea. ${ }^{20}$ The FOTbased phenotyping is correlated with the assessments of CT parameters. Thus, the pathophysiological heterogeneity of COPD could be reflected to different FOT-based phenotypes.

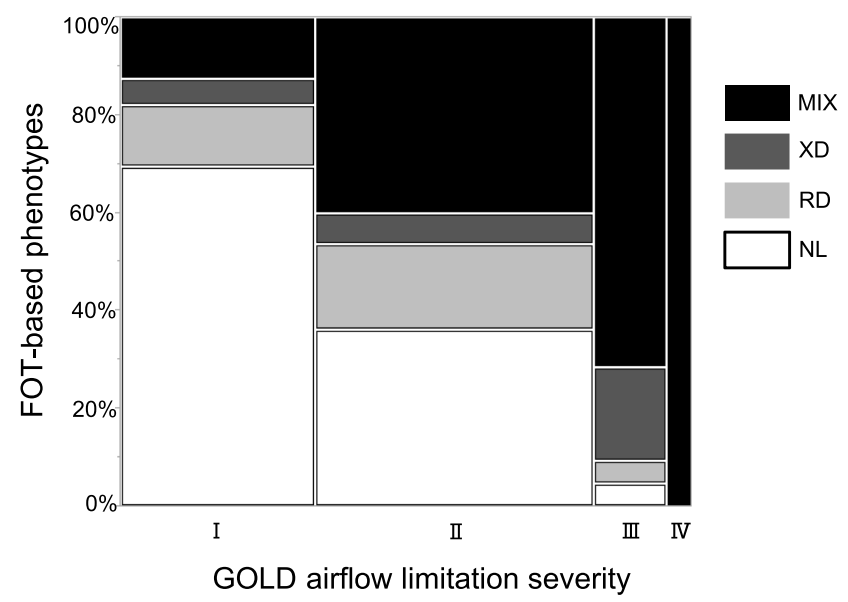

Figure 3 Definition of the four novel FOT-based phenotypes by the GOLD classification of airflow limitation severity.

Abbreviations: FOT, forced oscillation technique; GOLD, Global Initiative for Chronic Obstructive Lung Disease; MIX, mixed group; NL, normal group; RD, resistance-dominant group; $\mathrm{XD}$, reactance-dominant group. 
Recently, Karayama et al reported that emphysematous lesions in chest CT do not associate with Rrs indices but are significantly correlated with some Xrs indices. ${ }^{12}$ Conversely, Wada et al demonstrated a lack of significant correlation of both Rrs and Xrs with emphysematous lesions, but both were correlated with $\sqrt{ }$ Aaw at Pi10 as an indicator of airway wall thickness in COPD. ${ }^{11}$ Both opinions do not contradict our FOT-based phenotyping. R5 may purely reflect airway lesions and X5 may reflect the both gas-trapping area and airway lesions, both of which eventually shift to emphysema. Destruction of the lung parenchyma leads to the loss of bronchiolar-alveolae attachments. As a result, gas-trapping, emphysematous changes and airway lesions are occurred in COPD patients. FOT-based phenotyping could both assess Rrs and Xrs and reflect pathophysiological heterogeneity.

Spirometry is also a useful functional assessment to reveal airway obstruction such as $\mathrm{FEV}_{1} / \mathrm{FVC}$ and $\mathrm{FEV}_{1} \%$ predicted. However, it is difficult to conclusively identify the cause of obstructive functional changes. As shown in Figure 3, severe and very severe GOLD categories comprise mainly the MIX group. However, all FOT-based phenotypes are presented in mild and moderate GOLD categories. With combined assessment of Rrs and Xrs, the FOT-based phenotyping could represent the pathophysiological heterogeneity in COPD from a new perspective.

Notably, the FOT-based phenotyping is a simple and useful assessment which could reflect the pathophysiology of COPD caused by both emphysematous lesions and airway lesions.

This study has several limitations. First, this was a single-center and retrospective study. Second, the nonCOPD smokers in this study were ruled out COPD by definitions but they visited our outpatient clinic because they presented symptoms such as cough. For the FOTbased phenotyping, this may have caused stricter cut-off values in our population of non-COPD smokers compared to a healthy control population. Hence, we used the 3 rd quartile instead of the mean $+2 \mathrm{SD}$ of the $\mathrm{R} 5$ and $\mathrm{X} 5$ values. Further, the number of the non-COPD patients was relatively small. Finally, two different FOT devices, namely, MasterScreen-IOS ${ }^{\circledR}$ (CareFusion Germany $234 \mathrm{GmbH}$, Germany) and the MostGraph ${ }^{\circledR}$ (Chest M.I., Inc., Tokyo, Japan), are widely used, and they do not always generate identical respiratory impedance values. ${ }^{25}$ Further studies are needed to elucidate the influence of functional changes on quantitative imaging parameters.

\section{Conclusion}

The FOT-based phenotyping may be safe and useful to assess pathophysiological changes of COPD with CT assessments.

\section{Ethics Approval and Informed Consent}

This study was approved by the Ethics Committee of SUMS (registration number: 27-11) and conformed to the tenets of the Declaration of Helsinki, and all patients provided written informed consent prior to their participation.

\section{Acknowledgments}

The authors would like to thank the secretary, Ms. Yoko Naito, and the technicians, Ms. Mayuko Ono and Mr. Hayato Okumura, for their continued help throughout the study. This paper was presented at the American Thoracic Society InternationalConference 2019 as a conference talk with interim findings. The abstract was published in "Conference Abstracts" in American Journal of Respiratory and Critical Care Medicine 2019, Volume 199.

\section{Author Contributions}

Yumiko Matsuo contributed to the analysis and the interpretation of data and wrote the initial draft of the manuscript. Emiko Ogawa designed the study, contributed to the interpretation of data, and assisted in the preparation of the manuscript. All authors made substantial contributions to conception and design, acquisition of data, or analysis and interpretation of data; took part in drafting the article or revising it critically for important intellectual content; gave final approval of the version to be published; and agree to be accountable for all aspects of the work.

\section{Disclosure}

HK reports personal fees from Chest M.I. Inc., during the conduct of the study. In addition, HK has a patent for a 3D graphic technique in forced oscillation technique apparatus of MostGraph and a patent for a noise reduction technique in forced oscillation technique apparatus of MostGraph. The authors report no other conflicts of interest in this work.

\section{References}

1. Nakano Y, Muro S, Sakai H, et al. Computed tomographic measurements of airway dimensions and emphysema in smokers. Correlation with lung function. Am J Respir Crit Care Med. 2000;162(3 Pt 1):1102-1108. doi:10.1164/ajrccm.162.3.9907120 
2. Tho NV, Ryujin Y, Ogawa E, et al. Relative contributions of emphysema and airway remodelling to airflow limitation in COPD: consistent results from two cohorts. Respirology. 2015;20(4):594-601. doi:10.1111/resp.12505

3. Nakano Y, Wong JC, de Jong PA, et al. The prediction of small airway dimensions using computed tomography. Am J Respir Crit Care Med. 2005;171:142-146. doi:10.1164/rccm.200407-874OC

4. Galban CJ, Han MK, Boes JL, et al. Computed tomography-based biomarker provides unique signature for diagnosis of COPD phenotypes and disease progression. Nat Med. 2012;18(11):1711-1715. doi: $10.1038 / \mathrm{nm} .2971$

5. Bhatt SP, Soler X, Wang X, et al. Association between functional small airway disease and FEV1 decline in chronic obstructive pulmonary disease. Am J Respir Crit Care Med. 2016;194(2):178-184. doi:10.1164/rccm.201511-22190C

6. Boes JL, Hoff BA, Bule M, et al. Parametric response mapping monitors temporal changes on lung CT scans in the subpopulations and intermediate outcome measures in COPD Study (SPIROMICS). Acad Radiol. 2015;22(2):186-194. doi:10.1016/j. acra.2014.08.015

7. Pompe E, Galban CJ, Ross BD, et al. Parametric response mapping on chest computed tomography associates with clinical and functional parameters in chronic obstructive pulmonary disease. Respir Med. 2017;123:48-55. doi:10.1016/j.rmed.2016.11.021

8. Kirby M, Yin Y, Tschirren J, et al. A novel method of estimating small airway disease using inspiratory-to-expiratory computed tomography. Respiration. 2017;94(4):336-345. doi:10.1159/000478865

9. Shirai T, Kurosawa H. Clinical application of the forced oscillation technique. Intern Med. 2016;55:559-566. doi:10.2169/internalmedicine. 55.5876

10. Oostveen E, MacLeod D, Lorino H, et al. The forced oscillation technique in clinical practice: methodology, recommendations and future developments. Eur Respir J. 2003;22(6):1026-1041. doi:10.1183/09031936.03.00089403

11. Wada Y, Kitaguchi Y, Yasuo M, et al. Diversity of respiratory impedance based on quantitative computed tomography in patients with COPD. Int J Chron Obstruct Pulmon Dis. 2018;13:1841-1849. doi:10.2147/COPD

12. Karayama M, Inui N, Mori K, et al. Respiratory impedance is correlated with morphological changes in the lungs on three-dimensional CT in patients with COPD. Sci Rep. 2017;7:41709.

13. Global strategy for the diagnosis, management and prevention of Chronic Obstructive Lung Disease 2019 report. [homepage on the Internet] Global Initiative for Chronic Obstructive Lung Disease. 2019. Available from: https:/goldcopd.org/wp-content/uploads/2018/11/GOLD-2019-v1. 7-FINAL-14Nov2018-WMS.pdf. Accessed July 30, 2019.
14. Mirza S, Clay RD, Koslow MA, Scanlon PD. COPD guidelines: a review of the 2018 GOLD report. Mayo Clin Proc. 2018;93 (10):1488-1502. doi:10.1016/j.mayocp.2018.05.026

15. Jones PW, Harding G, Berry P, Wiklund I, Chen WH, Kline Leidy N. Development and first validation of the COPD Assessment Test. Eur Respir J. 2009;34(3):648-654. doi:10.1183/09031936.00102509

16. Fletcher CM. Standardised questionnaire on respiratory symptoms: a statement prepared and approved by the MRC Committee on the Aetiology of Chronic Bronchitis (MRC breathlessness score). BMJ Open. 1960;2:1665.

17. Miller MR, Hankinson J, Brusasco V, et al. Standardisation of spirometry. Eur Respir J. 2005;26(2):319-338. doi:10.1183/0903 1936.05.00034805

18. Sasaki H, Nakamura M, Kida K, et al. Reference values for spirogram and blood gas analysis in Japanese adults. J Japan Respir Soc. 2001;39:S1-S17.

19. Ohishi J, Kurosawa H, Ogawa H, Irokawa T, Hida W, Kohzuki M. Application of impulse oscillometry for within-breath analysis in patients with chronic obstructive pulmonary disease: pilot study. BMJ Open. 2011;1(2):e00184. doi:10.1136/bmjopen-2011-000184

20. Van Tho N, Ogawa E, Trang Le TH, et al. A mixed phenotype of airway wall thickening and emphysema is associated with dyspnea and hospitalization for chronic obstructive pulmonary disease. Ann Am Thorac Soc. 2015;12(7):988-996. doi:10.1513/AnnalsATS.201411-501OC

21. Di Mango AM, Lopes AJ, Jansen JM, Melo PL. Changes in respiratory mechanics with increasing degrees of airway obstruction in COPD: detection by forced oscillation technique. Respir Med. 2006;100(3):399-410. doi:10.1016/j.rmed.2005.07.005

22. Ogawa E, Nakano Y, Ohara T, et al. Body mass index in male patients with COPD: correlation with low attenuation areas on CT. Thorax. 2009;64:20-25. doi:10.1136/thx.2008.097543

23. Higami Y, Ogawa E, Ryujin Y, et al. Increased epicardial adipose tissue is associated with the airway dominant phenotype of chronic obstructive pulmonary disease. PLoS One. 2016;11(2):e0148794. doi:10.1371/journal.pone.0148794

24. Van Tho N, Wada H, Ogawa E, Nakano Y. Recent findings in chronic obstructive pulmonary disease by using quantitative computed tomography. Respir Investig. 2012;50(3):78-87. doi:10.1016/j.resinv. 2012.08.002

25. Tanimura K, Hirai T, Sato S, et al. Comparison of two devices for respiratory impedance measurement using a forced oscillation technique: basic study using phantom models. J Physiol Sci. 2014;64 (5):377-382. doi:10.1007/s12576-014-0329-4

\section{Publish your work in this journal}

The International Journal of COPD is an international, peer-reviewed journal of therapeutics and pharmacology focusing on concise rapid reporting of clinical studies and reviews in COPD. Special focus is given to the pathophysiological processes underlying the disease, intervention programs, patient focused education, and self management protocols. This journal is indexed on PubMed Central, MedLine and CAS. The manuscript management system is completely online and includes a very quick and fair peer-review system, which is all easy to use. Visit http://www.dovepress.com/testimonials.php to read real quotes from published authors. 